\title{
Influence of oophorectomy on glycemia and lipidogram ${ }^{1}$
}

Renan Kleber Costa Teixeira', Daniel Haber Feijó", André Lopes Valente"II, Luan Teles Ferreira de Carvalho'v , Hícaro Donato Granhen ${ }^{\mathrm{v}}$, Andy Petroianu ${ }^{\mathrm{v}}$, Nara Macedo Botelhovil

'Fellow Master degree, Postgraduate Program in Surgery and Experimental Research, Universidade do Estado do Pará (UEPA), Belem-PA, Brazil. Conception, design, intellectual and scientific content of the study; interpretation of data; manuscript writing.

"MD, Department of Experimental Surgery, School of Medicine, UEPA, Belem-PA, Brazil. Interpretation of data, manuscript writing.

"'Graduate student, School of Medicine, UEPA, Belem-PA, Brazil. Acquisition and interpretation of data.

IVGraduate student, School of Medicine, Universidade Federal do Pará (UFPA), Belem-PA, Brazil. Acquisition and interpretation of data.

vGraduate student, School of Medicine, Faculdade Metropolitana da Amazônia, Belem-PA, Brazil. Acquisition and interpretation of data.

VIPhD, Full Professor, Department of Surgery, School of Medicine, Universidade Federal de Minas Gerais (UFMG), Belo Horizonte-MG, Brazil. Conception, design, intellectual and scientific content of the study; critical revision, final approval. VIIPhD, Full Professor, Department of Gynecology, School of Medicine, UEPA, Belem-PA, Brazil. Conception, design, intellectual and scientific content of the study; critical revision.

\section{Abstract}

Purpose: To verify the influence of oophorectomy on lipidogram and glycemia.

Methods: Fifty six female rats were divided into the following 7 groups $(n=8)$ : group 1 sham group, group 2 - oophorectomy 30 days, group 3 - oophorectomy 35 days, group 4 oophorectomy 40 days, group 5 - oophorectomy 45 days, group 6 - oophorectomy 70 days, group 7 - oophorectomy 55 days. Animals were following by number of days according the group. Was evaluated the serum levels of glucose and lipid profile.

Results: The oophorectomized rats presented higher glycemia. Groups 3, 4, 6 and 7 had a higher glycemia and LDL levels (except for group 6 ) and groups 6 and 7 had lowest levels of HDL. Group 7 had highest level of VLDL than oophorectomy groups. There was no difference in triglycerides levels.

Conclusion: Oophorectomy was related to dyslipidemia and insulin resistance, mainly after 50th days.

Key words: Ovariectomy. Climacteric. Dyslipidemias. Rats. 


\section{Introduction}

Low incidence of cardiovascular diseases has been reported in women due to protective hormone effect ${ }^{1-3}$. These illnesses are rare in the premenopausal period, because high levels of estrogen acts improving lipid profile by reducing cholesterolemy. After menopause, hormones promote an increase in weight ${ }^{1,2,4}$, high insulin resistance ${ }^{2-5}$ and high blood pressure ${ }^{1,3-5}$. In addition to lipidogram changes, leading to an atherogenic lipoprotein profile.

Cholesterol and triglycerides levels are influenced by several factors ${ }^{4,6,7}$, such as: diet, life style, age, sex, changes in spleen e hormonal changes. The women's lipid profile has a high influence of this hormonal change, since physiological fluctuations in menstrual cycle change the lipidogram and glycemia ${ }^{8}$. Showing the importance of these sexual hormones. However, mechanisms underlying the influence of hormone in metabolism are controversial yet.

Human studies are being poorly feasible, so, experimental animal model can be used in medical testing to resemble events occurring among the human being as their genetic, biological and behavior characteristics mimic those of human ${ }^{9}$. Rodents are excellent experimental model of dyslipidemia, because they pass through hormonal fluctuations occurring in middle age, similar to those in women. However, rodents enter an estropause rather than a true menopause. Rodents show irregular acyclicity at middle age, after which, they enter a state of persistent estrus, with complete stoppage of reproductive cycles ${ }^{10,11}$.

Due the importance of risk factors caused by oophorectomy and your relationship with lipid profile and insulin resistance, this paper aims to verify the influence of oophorectomy on lipidogram and glycemia.

\section{Methods}

This research followed the rules of the Brazilian Law for Animal Care (Law: 11.794/08) and was approved by the Animal Use and Care Committee, Universidade do Estado do Para (protocol № 22/11).

Fifty-six Wistar female rats (Rattus norvegicus) were kept in a controlled environment, with food and water ad libitum. All animals had the same birth date, 90 days old at baseline and were randomly divided into the following seven groups $(n=8)$ :

Group 1 - Sham - identification and manipulation of the ovaries without removing them.

Group 2 - Bilateral oophorectomy and followed during 30 days after surgery.

Group 3 - Bilateral oophorectomy and followed during 35 days after surgery.

Group 4 - Bilateral oophorectomy and followed during 40 days after surgery.

Group 5 - Bilateral oophorectomy and followed during 45 days after surgery.

Group 6 - Bilateral oophorectomy and followed during 50 days after surgery.

Group 7 - Bilateral oophorectomy and followed during 55 days after surgery.

All surgical procedures were performed in anesthesia (ketamine and xylazine 70 and $10 \mathrm{mg} / \mathrm{kg}$, respectively, IP). The bilateral oophorectomy was performed similar to described by Brito et al. ${ }^{12}$. At the end of the following period, $5 \mathrm{ml}$ of blood was collected from vena cava for glucose, cholesterol fractions and triglyceride studies, using colorimetric assay, using kits from Labtest ${ }^{\circ}$. The animals were killed under deep anesthesia by intravenous injection of $\mathrm{KCl}$.

The software BioEstat ${ }^{\odot} 5.4$ was used. All data were expressed as means \pm standard deviation. The serum levels of glucose and lipid profile were comparing by analysis of 
variance (ANOVA), followed by Tukey post hoc test correction when necessary. Statistical significance was assumed at $p<0.05$.

\section{Results}

All animals survived during the study period. Table 1 presents the mean and standard error of mean glycemia and lipidograms of the 7 groups. Regarding the measurement of serum glucose, the groups 3, 4, 6 and 7 had a higher level than group $1(p<0.01)$. With respect to total cholesterol, only the groups 2 ,
3 and 4 had a significant increase than group 1 $(p<0.01)$.

By analyzing the cholesterol fractions, the groups 2 and 3 had increased and groups 6 and 7 had a reduction of HDL levels, comparing to group 1; already in relation to $L D L$, the group 7 show higher levels than group $1(p=0.02)$. The group 7 had the highest levels of VLDL than other oophorectomy groups $(p<0.01)$, however, its had similar levels than groups 1. There was no statistically significant difference in the analysis of serum triglycerides.

Table 1 - Mean levels of serum glucose, total cholesterol and fractions and triglycerides according groups.

\begin{tabular}{|c|c|c|c|c|c|c|c|}
\hline \multirow{2}{*}{ Parameter } & \multicolumn{7}{|c|}{ GROUP } \\
\hline & 1 & 2 & 3 & 4 & 5 & 6 & 7 \\
\hline Glucose & $144 \pm 27$ & $236 \pm 86^{*}$ & $253 \pm 53^{*}$ & $165 \pm 22$ & $148 \pm 20$ & $219 \pm 44^{*}$ & $230 \pm 67^{*}$ \\
\hline Total Cholesterol & $69 \pm 15$ & $136 \pm 32$ & $124 \pm 34$ & $86 \pm 34$ & $78 \pm 16$ & $62 \pm 20$ & $84 \pm 21$ \\
\hline HDL & $11 \pm 9.7$ & $23 \pm 9.0$ & $36 \pm 5.7^{*}$ & $22 \pm 14.6$ & $15 \pm 3.4$ & $02 \pm 1.8^{*}$ & $02 \pm 1.8^{*}$ \\
\hline LDL & $45 \pm 12$ & $107 \pm 35^{*}$ & $80 \pm 32 *$ & $56 \pm 24$ & $54 \pm 18$ & $48 \pm 19$ & $65 \pm 19 *$ \\
\hline VLDL & $12 \pm 4.6$ & $06 \pm 1.6$ & $08 \pm 2.4$ & $09 \pm 4.9$ & $08 \pm 4.4$ & $11 \pm 5.6$ & $16 \pm 7.4^{*}$ \\
\hline Triglycerides & $62 \pm 23$ & $30 \pm 8.2$ & $39 \pm 11$ & $44 \pm 24$ & $41 \pm 21$ & $56 \pm 28$ & $83 \pm 37$ \\
\hline
\end{tabular}

\section{- Discussion}

The mechanism by which ovarian hormones affect the women's physiology still not fully understood. However, the lack of these, due to ovarian failure (menopause) or surgical removal (oophorectomy) is associated with development of adverse conditions, such as: obesity ${ }^{4,13}$, diabetes ${ }^{4,5}$ and dyslipidemia ${ }^{4,5}$. Possibly these changes are linked to estrogen action, once the replacement of only estrogen in menopause rats and humans decrease the plasma cholesterol levels and glycemia ${ }^{14,15}$.

Weinitiated thesestudies tocharacterize the better time to evaluation the lipidogram and glycemia levels in oophorectomized rats, since this time is not well defined. Cholesterol total was maintained at similar levels in all groups ( $p>0.05$ ), however, its fractions showed a decrease of $\mathrm{HDL}$ and increase of LDL and VLDL, mainly from the group 6 (50 days). Wellknown that after oophorectomy, sex hormones circulate in the body at a high level for 2130 days $^{11,12}$. Therefore, groups 2 to 5 were in adaptation to new condition of hormonal suppression, explaining fluctuations of serum levels identified in this period (30-45 days). Thus, studies evaluating these parameters at this time may be harmed.

In more than sixty days follow-up of oophorectomized rats ${ }^{16-18}$, studies show similar levels of plasma cholesterol and glucose than groups 6 and 7 . These findings strengthen the possibility that it is necessary at least fifty days 
for adaptation to hormonal suppression.

Triglycerides have a close relationship with diet and energy consumption, however is slightly influenced by sexual hormones. Vasconcellos et al. ${ }^{13}$ reported that oophorectomy does not imply changes in dietary habits on female rats. Some studies that show increase of triglycerides have a bigger follow-up than this study and probably the obesity, associate to oophorectomy, influence the serum levels.

Menopause is associated with an increased risk of development of diabetes ${ }^{19}$, related to increase of insulin resistance caused by estrogen depletion. The glycemia, as plasma cholesterol levels, shows fluctuations of serum levels (groups 2 to 5 ) before the fifty days of post-operation; strengthen the hypothesis of adaptation to hormonal suppression. This hormonal influence is important to be highlighted, because after menopause other risk factors involved in insulin resistance happen ${ }^{4,5,19}$, such as obesity and muscle loss.

The data from this study favors the early use of hormone replacement in women, since the earlier they are used, the lower the metabolic changes suffered by women and the less the side effects they may present. However, more studies are needed to confirm these promising findings.

We limited to study the effects of oophorectomy on rats in lipidogram and glycemia in the first days of post-operative, to understand better the physiology. Meanwhile, it is necessary more studies evaluation the liver metabolism to confirm these findings and with a longer follow-up, correlated with weight of the animals.

\section{Conclusion}

Oophorectomy was related to dyslipidemia and insulin resistance, mainly after $50^{\text {th }}$ days.

\section{References}

1- Castanho VS, Nakamura RT, Pinto-Neto AM, Faria EC. Postmenopausal therapy reduces catalase activity and attenuates cardiovascular risk. Arq Bras Cardiol. 2012 Nov;99(5):1008-14. PMID: 23108643.

2- Versiani CM, Freire AC, Dias GMM, Brito BD, Rocha JSB, Reis VMCP. Evaluation of cardiovascular risk in climacteric women aided by Family Health Program. Rev Bras Clin Med São Paulo. 2013;11(4):1-5.

3- Schierbeck LL, Rejnmark L, Tofteng CL, Stilgren L, Eiken P, Mosekilde L, Køber L, Jensen JB. Effect of hormone replacement therapy on cardiovascular events in recently postmenopausal women: randomised trial. BMJ. 2012 Oct;345:e6409. doi: 10.1136/ bmj.e6409.

4- AnikóP, RenátaS, Krisztinak, Csonka A, Szalai Z, Veszelka M, Török S, Daruka L, Varga C. Exercise training and calorie restriction influence the metabolic parameters in ovariectomized female rats. Oxid Med Cell Longev. 2015; 2015:787063. doi: 10.1155/2015/787063.

5- Wang L, Szklo M, Folsom AR, Cook NR, Gapstur SM, Ouyang P. Endogenous sex hormones, blood pressure change, and risk of hypertension in postmenopausal women: the Multi-Ethnic Study of Atherosclerosis. Atherosclerosis. 2012 Sep;224(1):228-34. doi: 10.1016/j.atherosclerosis.2012.07.005.

6- Widén $E$, Silventoinen $K$, Sovio $U$, Ripatti $S$, Cousminer DL, Hartikainen AL, Laitinen J, Pouta A, Kaprio J, Järvelin MR, Peltonen $\mathrm{L}$, Palotie A. Pubertal timing and growth influences cardiometabolic risk factors in adult males and females. Diabetes Care. 2012 Apr;35(4):850-6. doi:10.2337/dc111365.

7- Petroianu A, Veloso DF, Alberti LR, Vasconcellos LS. Plasma lipid alterations after total splenectomy, subtotal splenectomy and splenic auto-implants in rats. J Gastroenterol Hepatol. 2008 Jul;23(7 Pt 2):e221-4. doi: 10.1111/j.14401746.2007.05263.x.

8- Kleiblová P, Springer D, Haluzík M. The influence of hormonal changes during menstrual cycle on serum adiponectin concentrations in healthy women. Physiol Res. 2006;55(6):661-6. PMID: 17177633. 
9- Chakraborty C, Hsu CH, Wen ZH, Lin CS, Agoramoorthy G. Zebrafish: a complete animal model for in vivo drug discovery and development. Curr Drug Metab. 2009;10:116-24. PMID: 19275547.

10-Maffucci JA, Gore AC. Age-related changes in hormones and their receptors in animal models of female reproductive senescence. In: Conn MP, editor. In Handbook of models for human aging. San Diego: Academic Press and Elsevier; 2006. pp. 533-52.

11-Frick KM. Estrogens and age-related memory decline in rodents: what have we learned and where do we go from here? Horm Behav. 2008;55:2-23. doi: 10.1016/j. yhbeh.2008.08.015.

12-Brito NMB, Carvalho RKV, Matos LTMB, Lobato RC, Brito RB. The oophorectomy effect on Walker 256 tumor inoculated into the vagina and uterine cervix of female rats. Acta Cir. Bras. 2009;24(1):26-9. PMID: 19169538.

13-Vasconcellos LS, Leite JM, Sabino KR, Petroianu A. Influence of oophorectomy on the weight variance in young and adult female rats. Arq Bras Endocrinol Metab. 2004;48(2):299-304. doi: /S000427302004000200014.

14-Lundeen SG, Carver JM, McKean ML, Winneker RC. Characterization of the ovariectomized rat model for the evaluation of estrogen effects on plasma cholesterol levels. Endocrinology.1997Apr;138(4):15528. doi: 10.1210/endo.138.4.5083.

15-Faulds $\mathrm{MH}$, Zhao C, Dahlman-Wright
K, Gustafsson JÅ. The diversity of sex steroid action: regulation of metabolism by estrogen signaling. J Endocrinol. 2012 Jan;212(1):3-12. doi: 10.1530/JOE-11-0044.

16-Hassan HA, Abdel-Wahhab MA. Effect of soybean oil on atherogenic metabolic risks associated with estrogen deficiency in ovariectomized rats: dietary soybean oil modulate atherogenic risks in overiectomized rats. J Physiol Biochem. 2012 Jun;68(2):247-53. doi: 10.1007/ s13105-011-0137-8.

17-Behr GA, Schnorr CE, Moreira JC. Increased blood oxidative stress in experimental menopause rat model: the effects of vitamin A low-dose supplementation upon antioxidant status in bilateral ovariectomized rats. Fundam Clin Pharmacol. 2012 Apr;26(2):235-49. doi: 10.1111/j.14728206.2010.00923.x.

18-Henriques HN, Câmara NR, de Carvalho AC, Pantaleão JA, Guzmán-Silva MA. Effect of high doses of tibolone in body weight and lipid profile of ovariectomized rats. Rev Bras Ginecol Obstet. 2010 Feb;32(2):88-93. PMID: 20305947.

19-Hoogeveen EK, Kostense PJ, Beks PJ, Mackaay AJ, Jakobs C, Bouter LM, Heine RJ, Stehouwer CD. Hyperhomocysteinemia is associated with an increased risk of cardiovascular disease, especially in noninsulin-dependent diabetes mellitus: a population-based study. Arterioscler Thromb Vasc Biol. 1998 Jan;18(1):133-8. PMID: 9445267.

\section{Correspondence:}

Renan Kleber Costa Teixeira

Rua Mundurucus, 2256/1401

66035-360 Belém - PA Brasil

Tel.: (55 91)98145-1108

renankleberc@hotmail.com

Received: Jan 26, 2018

Review: Mar 27, 2018

Accepted: Apr 25, 2018
Conflict of interest: none

Financial source: none
${ }^{1}$ Research performed at Laboratory of Experimental Surgery, Universidade do Estado do Pará (UEPA), Belem-PA, Brazil. 